ARGONNE NATIONAL LABORATORY

9700 South Cass Avenue

Argonne, Illinois 60440

\title{
CALORIMETRIC METHODS FOR THE ASSAY OF FUEL PINS AND RESIDUES
}

by

N. M. Lazar, S. Rosen, and A. B. Shuck

Portions of the work covered by this report have appeared in:

ANL-6099, Annual Report, Metallurgy Division, 1959, page 59. ANL-6677, Annual Report, Metallurgy Division, 1962, pages 195-198.

\author{
Metallurgy Division \\ Program 1.5 .8
}

November 1964
Operated by The University of Chicago under
Contract W-31-109-eng-38
with the
U. S. Atomic Energy Commission




\section{DISCLAIMER}

This report was prepared as an account of work sponsored by an agency of the United States Government. Neither the United States Government nor any agency Thereof, nor any of their employees, makes any warranty, express or implied, or assumes any legal liability or responsibility for the accuracy, completeness, or usefulness of any information, apparatus, product, or process disclosed, or represents that its use would not infringe privately owned rights. Reference herein to any specific commercial product, process, or service by trade name, trademark, manufacturer, or otherwise does not necessarily constitute or imply its endorsement, recommendation, or favoring by the United States Government or any agency thereof. The views and opinions of authors expressed herein do not necessarily state or reflect those of the United States Government or any agency thereof. 


\section{DISCLAIMER}

Portions of this document may be illegible in electronic image products. Images are produced from the best available original document. 
TABLE OF CONTENTS

Page

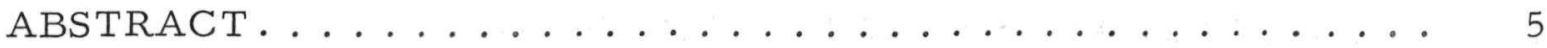

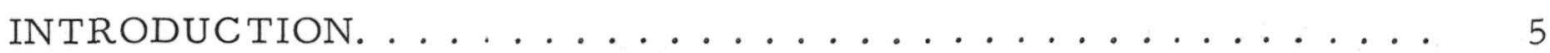

Feasibility of Calorimetric Assaying................. 6

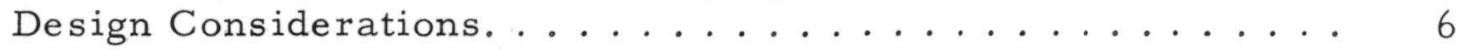

THE TWIN DIFFERENTIAL CALORIMETER. . . . . . . . . . . 9

Design of the Prototype Twin Calorimeter .......... 9

Performance of the Twin Calorimeter............ 12

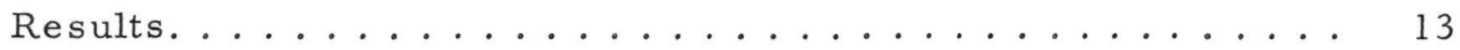

Automatic Control and Recording Equipment. . . . . . . 14

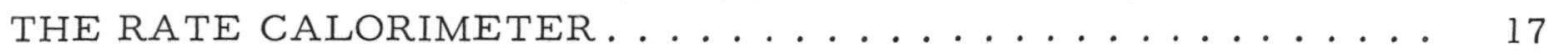

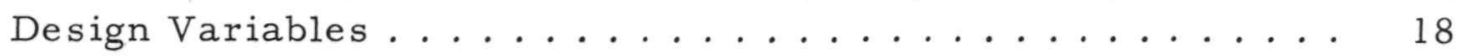

Preliminary Experimental Work.............. 21

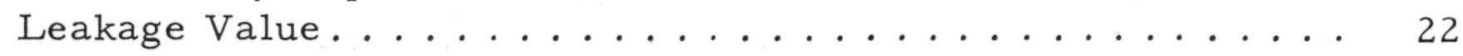

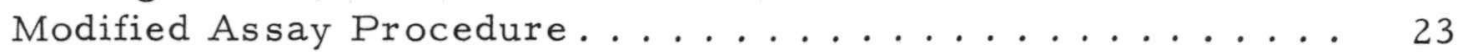

Further Work on the Rate Calorimeter. . . . . . . . . . . 24

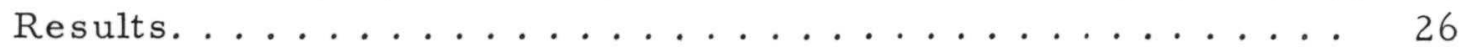

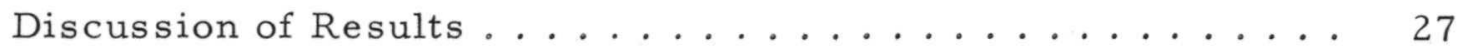

Recommendation for Further Modifications. . . . . . . . 28

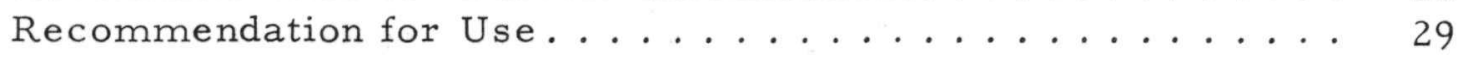

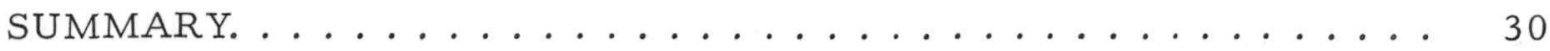

ACKNOWLEDGMENTS . . . . . . . . . . . . . . . . . . 31

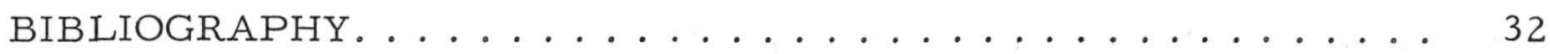

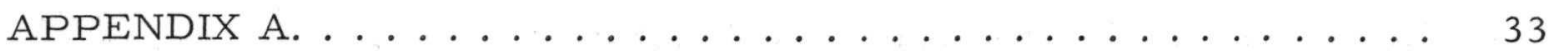

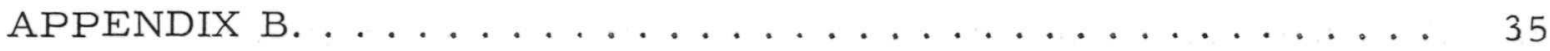




\section{LIST OF FIGURES}

No.

Title

Page

1. Watertight Can Assembly of Twin Calorimeter ........ 10

2. Watertight Assemblies of Twin Calorimeter ......... 10

3. Watertight Assemblies in Constant-temperature Bath Tank . . 10

4. Alternative Thermel Design for Twin Calorimeter....... 11

5. Simplified Wiring Circuits for Twin Calorimeter....... 12

6. Circuit Diagram for Twin Calorimeter............ 12

7. Block Diagram of Control and Indication for Twin

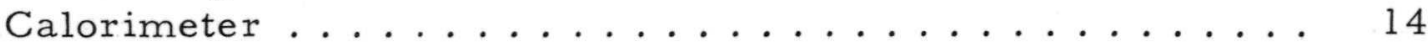

8. Control Cabinet for Twin Calorimeter........... 15

9. Wiring Diagram for Multiple Arrangement of Twin

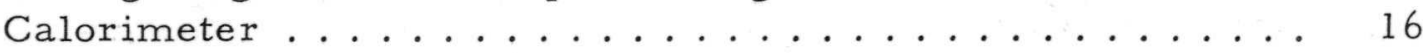

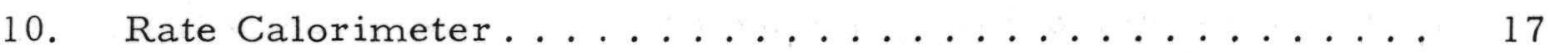

11. Rate Calorimeter, Current-Time Plot ........... 17

12. Experimental Circuit Diagram for Rate Calorimeter . . . . . 22

13. Calibration Curve for Rate Calorimeter........... 23

14. Circuit Diagram for Rate Calorimeter............ 24

15. Control Cabinet for Rate Calorimeter .......... 25

16. Current-Time Curves from Rate Calorimeter........ 26

17. Recorder Chart Showing Overshoot when Sample Inserted in

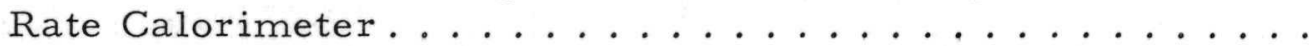

18. Recorder Chart Showing Desired Curve for Rate

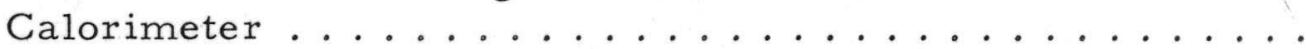




\title{
CALORIMETRIC METHODS FOR THE ASSAY \\ OF FUEL PINS AND RESIDUES
}

\section{by}

\author{
N. M. Lazar, S. Rosen, and A. B. Shuck
}

\begin{abstract}
The possibilities of using calorimetric methods for assay purposes in the Plutonium Facility and the EBR-II Fuel Reprocessing Facility were examined. Prototypes of twin-differential and rate calorimeters were assembled and experimentally investigated. These investigations indicate that calorimetric assay methods will be useful for these purposes. Based on results with the prototypes, more advanced calorimeters were constructed and are also described.
\end{abstract}

\section{INTRODUCTION}

It was anticipated that the Fuel Fabrication Facility (D-350) would generate large quantities of specimens, fuel pieces, and residues in which the plutonium content cannot be readily or accurately estimated by conventional means of sampling and analysis. Examples of such items are fuel specimens cast or extruded directly into jacket containers, composite fuels, and scrap from process. In the EBR-II Fuel Cycle Facility similar problems exist.

A rapid, nondestructive, integrating method for measuring the quantity of radioactive materials contained in such samples would be extremely useful in the operation of both the Fuel Fabrication Facility and the EBR-II Fuel Cycle Facility. The question of how much fuel is contained in clad specimens or a heterogeneous residue is not only of interest for reasons of accountability, but also must be solved for the useful evaluation of the specimens. A desirable method would integrate the total specimen and should not depend for its accuracy upon selection of a representative sample.

The total absorption of alpha radiation generates significant quantities of heat. In a given isotopic composition, the heat generated is directly proportional to the total quantity of plutonium or other alpha emitters in the specimen. This heat may be accurately measured by calorimetry. Consequently, calorimetric methods may be applied to the assay of nuclear fuels and process residues. 
Feasibility of Calorimetric Assaying

A survey of the literature indicated that radioactive heating was recognized very early as a possible assay method; Curie and Laborde ${ }^{(1)}$ used such a procedure to estimate the energy liberated by radium bromides. Methods of sufficient accuracy for the calibration of radioactive samples and standard sources have been developed. Improvements in calorimetry resulted from the development, by E. Rutherford and H. Robinson, (2) of the so-called "twin differential" calorimeter, which compensates for changes in environmental conditions. Further refinements in twin calorimetry have been made in recent years $(3-5)$ through the application of electronic feedback systems on control and power measurements. Improvement in the sensitivity by approximately 100 -fold over systems incorporating Wheatstone bridge galvanometer is said to have been achieved. The feedback system for increasing sensitivity appears to be limited only by the skill of the designer and constructor of the calorimeters and by the noise levels of the amplifying systems.

Jones and Jordan (4) have used twin calorimeters satisfactorily to measure energy output and to assay radioactive materials. They have constructed a number of such calorimeters of various sizes and sensitivities.

Adiabatic and isothermal calorimeters, nonadiabatic-nonisothermal rate calorimeters, and radio balances have been used for measurement of radioactive heating. Water baths have commonly been used for maintaining adiabatic or isothermal conditions. However, with suitable controls in conjunction with heaters, thermal shields, and insulating elements, controlled environments may be established with considerable accuracy without the use of a fluid bath. The possibility of using a liquid metal bath where water is not desirable should not be overlooked. The time required to make a measurement under adiabatic conditions is greater than that required under is othermal conditions.

A. G. White(6) has reported a prototype rate calorimeter that shows promise. It is claimed that such a calorimeter is simple to build and to operate, and that the measurement can be completed within an hour. This rate calorimeter is said to be flexible, and the same calorimeter may be used to measure sources with strength ratios of 1 to 1000 .

The radio balance appears to be a very delicate instrument and was not considered for the present application.

Design Considerations

The caloric outputs of samples from the EBR-II Reprocessing Facility were estimated to lie in the range between $7 \times 10^{-4}$ to $8 \times 10^{-3}$ $\mathrm{cal} / \mathrm{sec}-\mathrm{g}$. These energy emissions are significant and are of such magnitude that a caloric measurement can be completed rapidly enough to make 
it practical in routine work. The heat output of samples from the Plutonium Fabrication Facility is estimated at $0.002 \mathrm{~W} / \mathrm{g}$ of contained plutonium.

The size of the samples to be weighed can vary considerably. For example, pin samples may be as small as $4.77 \mathrm{~mm}$ (0.1875 in.) long, of $3.175-\mathrm{mm}$ (0.125-in.) diameter and weigh less than one gram. Crushed Vycor molds on the other hand, may occupy a volume of 1.5 liters. Such large variations in size of samples may necessitate the building of several calorimeters using common instrumentation.

Temperature measurements have been made with thermocouples, thermistors, and integrating sensing devices, such as platinum resistance coils. When thermocouples or thermistors are used, the position of the sample with respect to the temperature-sensing device affects the magnitude and accuracy of the measurement, whereas the results are independent of the location of the sample when a "thermel" (an integrating-type resistance sensor) is used. A feedback system in connection with an integrating thermel has resulted in a very high degree of accuracy. $(3,4)$ The electrical circuitry can be relatively simple or very elaborate, determined by the accuracy and sensitivity desired. The lead-wire-compensation method allows remote-control operation, making it adaptable to "hot cell" applications. (4)

The heat effect is characterized by the relationship

Heat input $=$ heat absorbed by the calorimeter + heat losses.

Heat input is the quantity that is sought and is determined by measuring the other two quantities.

Alpha or beta radiation is absorbed and converted into heat immediately. Gamma radiation is only partly absorbed. The effect of gamma radiation can be reduced considerably by using a calorimeter with a very thin wall. The attenuation of gamma rays can be included in the calibration of the calorimeter against a source of known strength.

Calorimetric assay methods appear to have the following advantages:

1. Calorimeters may be constructed for nearly any size or shape of sample.

2. They are integrating instruments that do not depend upon sampling techniques for their accuracy.

3. They may be constructed for use at elevated temperature as well as at low or room temperature.

4. The accuracy of calorimeters can be on a par with that of an analytical balance. 
5. The resistance-bridge type of calorimeter has an extremely wide range, possibly 1000:1 or greater. Where high accuracy is desired, the calorimeter should be designed to the geometry of the specimen.

From the above information it was concluded that twin calorimeters would be useful for assay work in Facility 350, for determination of the quantity of plutonium in sealed or jacketed specimens, and also for estimation of fuel content in the residues of the EBR-II Fuel Cycle Plant.

As the rate calorimeter, as proposed by White, (6) appeared to be a simple and inexpensive instrument for assay of radioactive substances, an instrument of this kind was constructed as well as a twin calorimeter. 


\section{THE TWIN DIFFERENTIAL CALORIMETER}

Calorimetric procedures are described by W. P. White, ${ }^{(8)}$ who also discusses the use of twin calorimeters. W. Swietoslawski $(1)$ describeis the uses of twin calorimeters in radiological work. More recent adaptation of twin calorimeters to assay of radioactive materials is discussed by A. J. Rogers, (9) who also gives an analysis of the heat flow and of electrical measurements, and describes the operation of the twin calorimeter for the assay of polonium. S. R. Gunn $(10)$ has also used the twin calorimeter for measurements of radioactive-source strength. He gives a simplified wiring diagram and instructions for operating the calorimeter.

The heat emitted by a constant-rate source such as radioactive sample may be determined by manual operation of a calorimeter. It is necessary only to permit the sample to come to thermal balance with the calorimeter and then to put electrical energy into the dummy side until the temperature of the sample side is reached. The electrical energy needed to balance thermally the two sides of the calorimeter is a measure of the heat emitted by the sample, provided the two sides are identical and that the temperature of the surroundings remains constant during the measurement. When a steady-state condition is reached, the heat loss from the calorimeter to the surroundings is equal to the heat given off by the sample. The temperature drop from the calorimeter to the surroundings is usually measured through an accurate air gap or some other poor thermal conductor. The air gap is carefully adjusted to the experimental conditions, especially to the magnitude of the heat effect.

There are several methods of operating twin calorimeters. In the "replacement method," the one most commonly used, the unknown is run on the sample side and then replaced by a calibrated heater or a standard source. The dummy side of the calorimeter is run empty or with an inert ballast to compensate for environmental variations. It is also possible to operate calorimeters by the "differential method," in which the unknown is run on one side and a standardized heater or standard radiation source is run on the other side of the calorimeter.

Design of the Prototype Twin Calorimeter

For the evaluation of the twin calorimeter for the Plutonium Facility, a prototype unit was designed and built. The calorimeter is adapted from those described by Rogers (9) and Gunn. (10) It consists of two watertight assemblies shown in Figures 1 and 2, immersed in a constant-temperature bath shown in Figure 3. The water bath may be replaced by any environment capable of being held at constant temperature. 


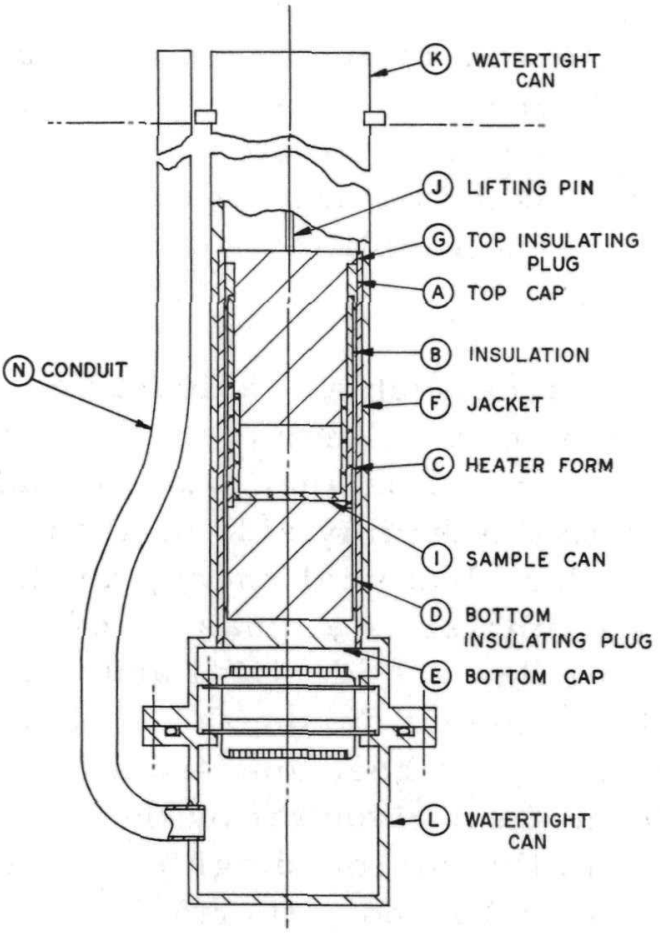

PF $-200-10$

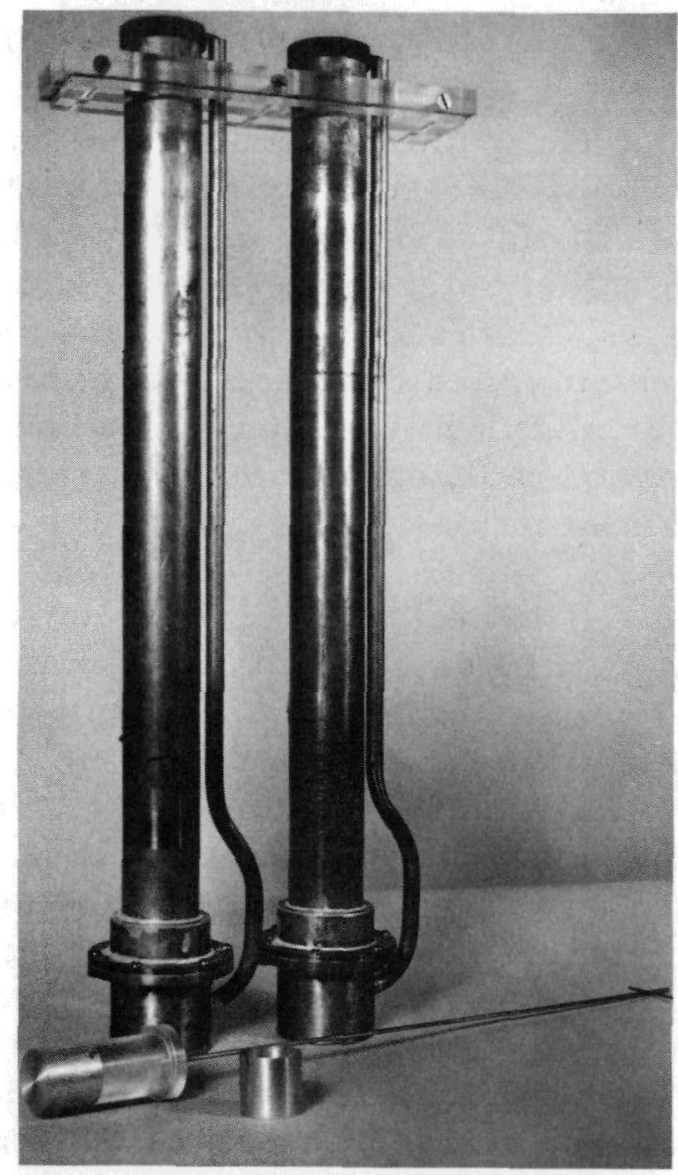

378

Fig. 1. Watertight Can Assembly of Twin Calorimeter

Fig. 2. Watertight Assemblies of Twin Calorimeter

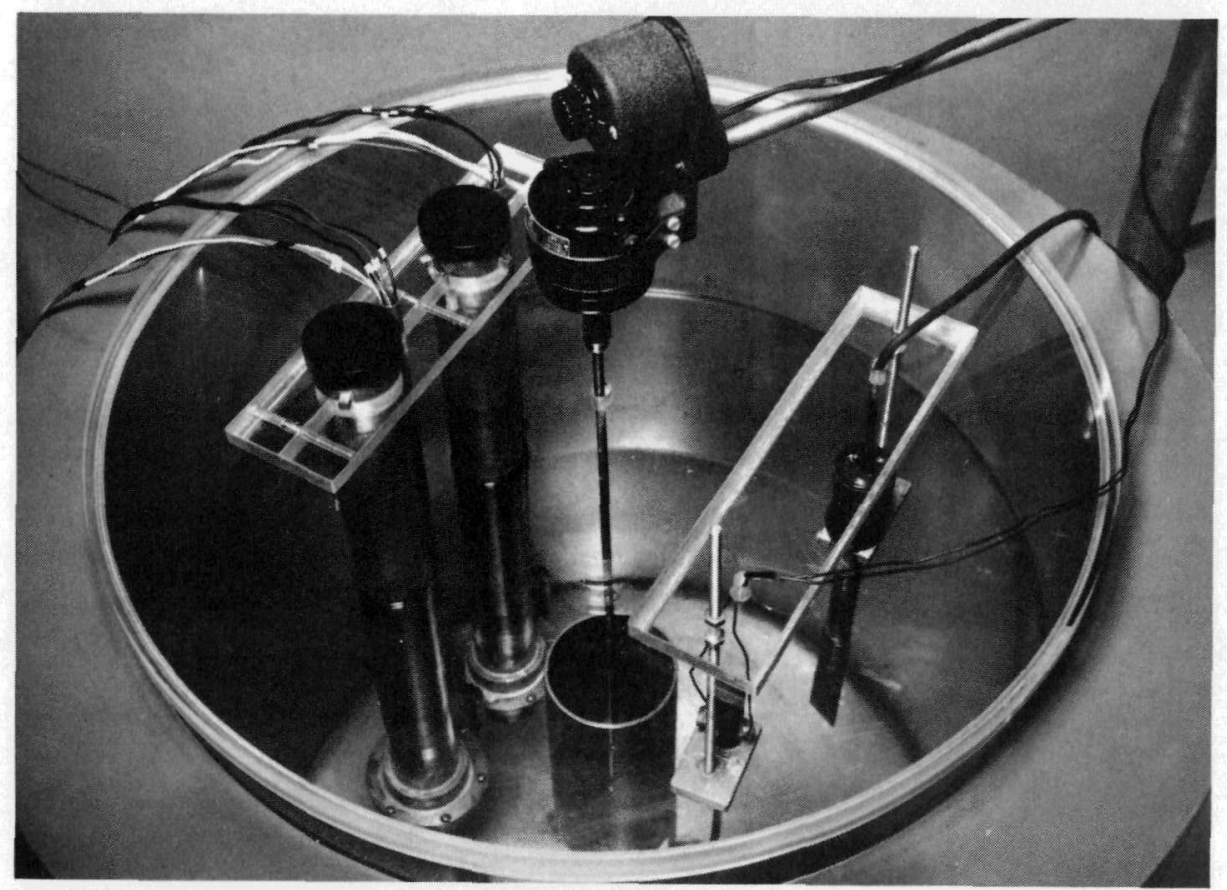

Fig. 3. Watertight Assemblies in Constant-temperature Bath Tank 
Figure 1 shows the component parts of a watertight assembly; Figure 2 is a photograph of the two completed watertight assemblies. It consists of a tube ( $\mathrm{K}$ in Figure 1 ) to accept the calorimeter proper and the associated thermels. The housing (L) contains the electrical connecting block. A conduit (N) permits connection of the lead wires from the thermels to the instruments. The remaining parts will have to be changed for each new calorimeter. The sample can (I) is inserted into the jacket, which has grooves for bifilar (noninductive) thermometer windings which sense the temperature of the surroundings. If the bath is controlled by a separate thermostat, then the winding on the jacket $(F)$ may be omitted.

The insulation (B), heater from (C), and bottom insulating plug (D) serve as forms for both heater and thermel, and are made of aluminum and Lucite, grooved for bifilar windings. An alternative design for the heater-thermel form, in which the heater is inside the thermal form, is suggested in Figure 4. This design has the advantage over that shown in

Figure 1, that it has a two-entry

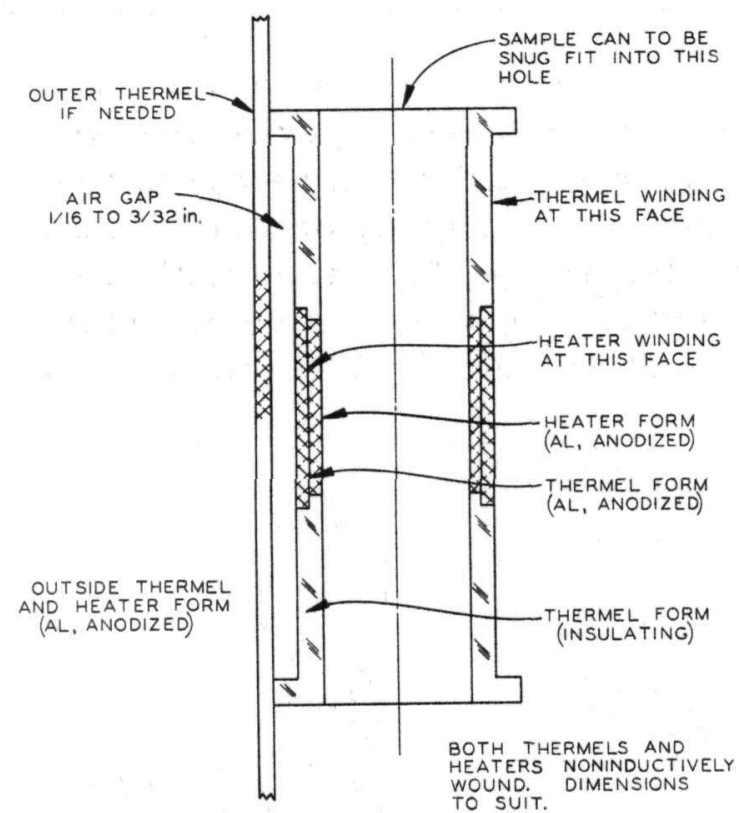

$P F-200-2$

Fig. 4. Alternative Thermel Design for Twin Calorimeter thread instead of a six-entry thread. This modified design is similar to the one used by Gunn.(10)

Essentially, the constanttemperature bath is an insulated container of 48-gal capacity. The bath temperature may be controlled by a thermostat or through thermels wound on the jacket of the watertight assembly. The thermel should be arranged as a bridge, similar to the calorimeter bridge. To maintain a uniform temperature throughout the bath, a motordriven propeller is used for circulation. The water is heated with an immersion heater.

Sufficient electrical instrumentation was on the site for initial operation and study of the prototype model. More sophisticated instrumentation

was designed after study of the prototype models indicated that further work was justified.

It is important to have a constant source of electric current for accurate calorimetric measurements. Ordinarily, a bank of low-discharge batteries is used for this purpose. The batteries are rather expensive and require constant attention. Stull $(i 1)$ and his coworkers have described a constant-power source for calorimetric application. They claim that this apparatus has operated satisfactorily with little attention over long periods of time. 
For automatic control and recording, it is desirable to use a voltage integrator device. There are a number of methods by which this may
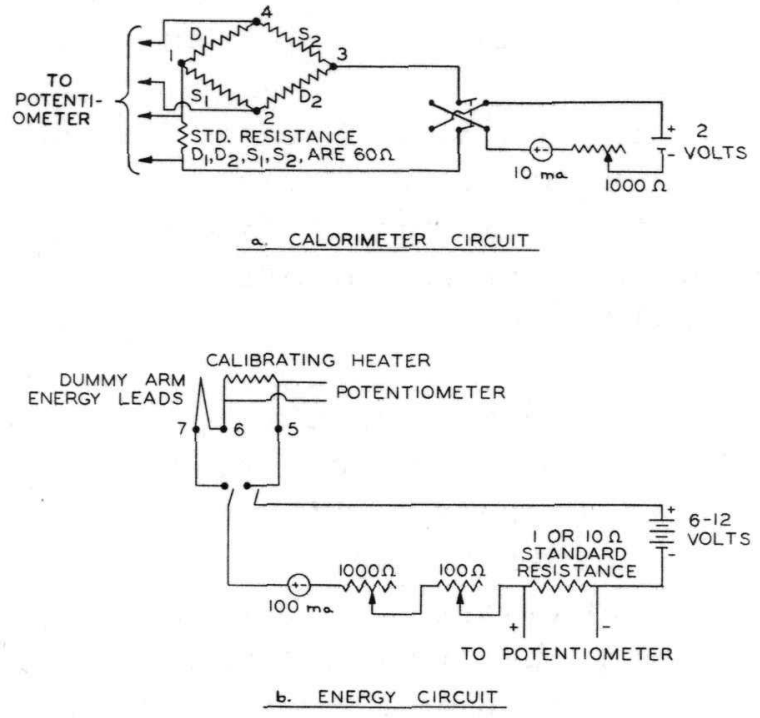

PF $-200-3$

Fig. 5. Simplified Wiring Circuits for Twin Calorimeter be accomplished; one such method is reported by Buzzell and Sturtevant.(12)

The simplest form of electrical circuit for this type of calorimeter is given by Beamer and Easton, (7) who used the twin calorimeter to measure the half-life of polonium. This circuit is shown in Figure 5a. When remote, in-cave operation is considered, the resistance of the lead wires may be compensated for by a wiring scheme suggested by Rogers. (9)

Performance of the Twin Calorimeter

After assembly of the calorimeter components, experiments were performed to determine operating technique, accuracy obtainable, and to compare performance with the

rate calorimeter. The circuit diagram used is shown in Figure 6, which is a modification of that given by Beamer and Easton. (7) The current and emf measurements were performed manually with a Leeds and Northrup Type $\mathrm{K}$ potentiometer and an electronic galvanometer. The bridge current was adjusted by 100-Ohm and $10-\mathrm{Ohm}$ variable resistors connected in series. The magnitude of the current was measured as a potential drop across a standardized 10-Ohm resistance.

The current for the calorimeter heater was adjusted with 500-, 100-, and 10-Ohm variable resistors connected in series, and was measured as a potential drop across a standardized one-Ohm resistance. The sample heater with measured power input and fuel slugs of known plutonium content were used as sample heat sources in separate experiments. The power was supplied by

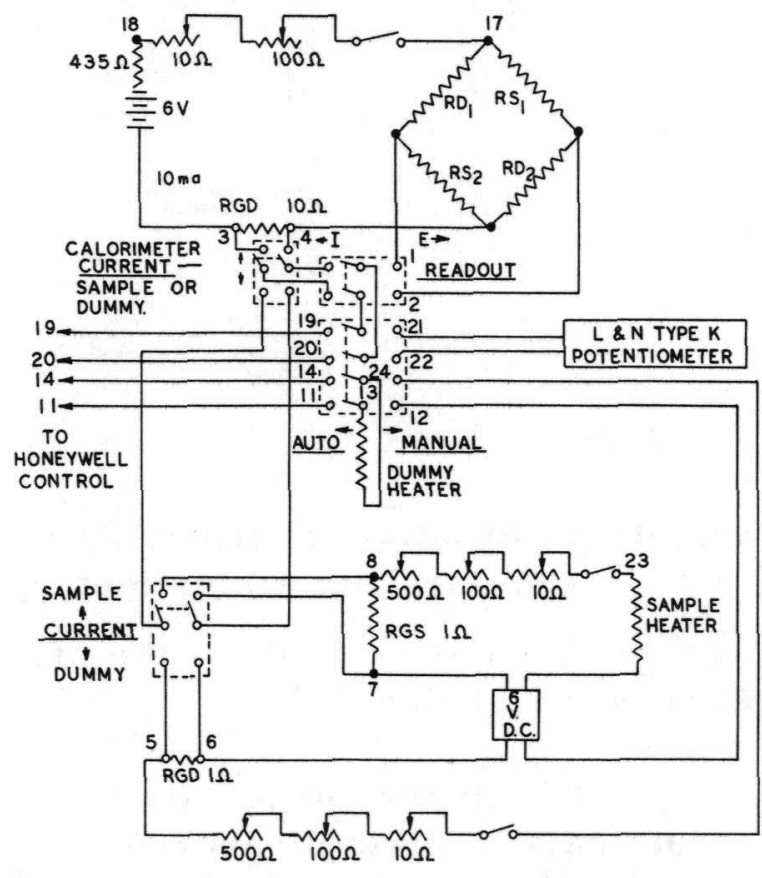

Fig. 6. Circuit Diagram for Twin Calorimeter 
a $6-\mathrm{V}$ battery. The temperature of the water bath was controlled within $0.05^{\circ} \mathrm{C}$. The performance of the calorimeter was evaluated by putting a known quantity of electrical power into the sample side and measuring it on the dummy side by a balancing power input. A second method used plutonium-aluminum alloy fuel slugs as a standard. The magnitude of the power input of the plutonium samples was calculated from the isotopic analysis by use of the decay formula and the energy-emission data of plutonium isotopes. (13)

Both Rogers(9) and Gunn(10) give the analysis of the heat flow and of the electrical measurements, and also describe the operation of the calorimeter. Rogers method of calculating the sample power has been used. His basic equation for the calorimeter is

$$
\Delta E_{B}(n e t)=S_{S} C_{s}-S_{d} C_{d}
$$

where

$$
\begin{aligned}
\Delta \mathrm{E}_{\mathrm{B}} \text { (net) } & =\text { change in bridge potential, } \mathrm{V} \\
\mathrm{S} & =\text { sensitivity of calorimeter, } \mathrm{V} / \mathrm{C} \text { or } \mathrm{V} / \mathrm{W} \\
\mathrm{C} & =\text { rate of emission of radioactive heat, } \mathrm{C} \text { or } \mathrm{W} .
\end{aligned}
$$

The subscripts $s$ and $d$ refer to sample and dummy side, respectively. The use of Equation 1 is explained in Appendix A.

Results

The prototype model operated very satisfactorily. The calorimeter operated with a reproducibility of \pm 0.25 percent even though temporary instrumentation and a simple control circuit were used. The operation of the calorimeter, interpretation of the data, and calculation of the results were simple and, indeed, significantly simpler than for the comparative rate calorimeter. It was observed that the same calorimeter constant and the same initial bridge-voltage value may be used in each calculation of the sample power in consecutive measurements. In comparison, the rate calorimeter demands that the calorimeter constants be evaluated during each test. Because of this, the operating time of the twin calorimeter is reduced to about the same duration as that of the rate calorimeter.

The theoretical power output of the Pu-Al alloy slugs was calculated to be $0.00210 \mathrm{~W} / \mathrm{g}$ of plutonium in the alloy; a value of $0.00229 \mathrm{~W} / \mathrm{g}$ was found experimentally. The experiment was repeated a month later and the energy output was found to be $0.00227 \mathrm{~W} / \mathrm{g}$. 
Sample data and calculations for the twin calorimeter are given in Appendix A.

Automatic Control and Recording Equipment

Automatic controlling and recording equipment, capable of automatically balancing the power output of the radioactive sample by feeding electric power continuously into the dummy side of the calorimeter, has been purchased. The power input is automatically integrated and recorded on a readout. An X-Y recorder is included, which can record either emf or wattage. The block diagram for this equipment is shown in Figure 7. A separate control panel is included for manual operation. The circuit diagram for manual operation is essentially the same as that shown in Figure 6. Figure 8 is a photograph of the assembled control cabinet.

Possibly the twin calorimeter could be used as a multiple calorimeter where several sample chambers could be used in conjunction with a common dummy chamber and using common instrumentation. The bridge circuit for such an instrument could be arranged as shown in Figure 9. This multiple arrangement would make it possible to conduct several determinations concurrently, resulting in considerable savings in time per determination.

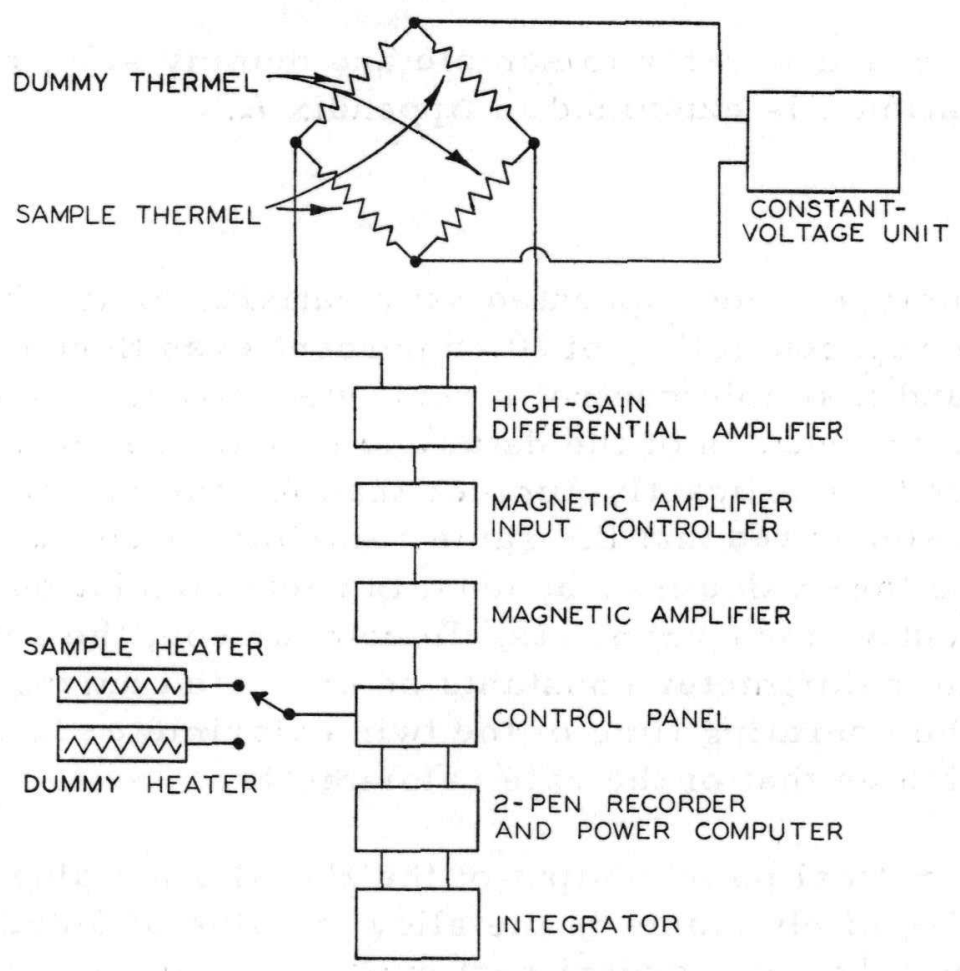

$\mathrm{PF}-200-11$

Fig. 7. Block Diagram of Control and Indication for Twin Calorimeter 


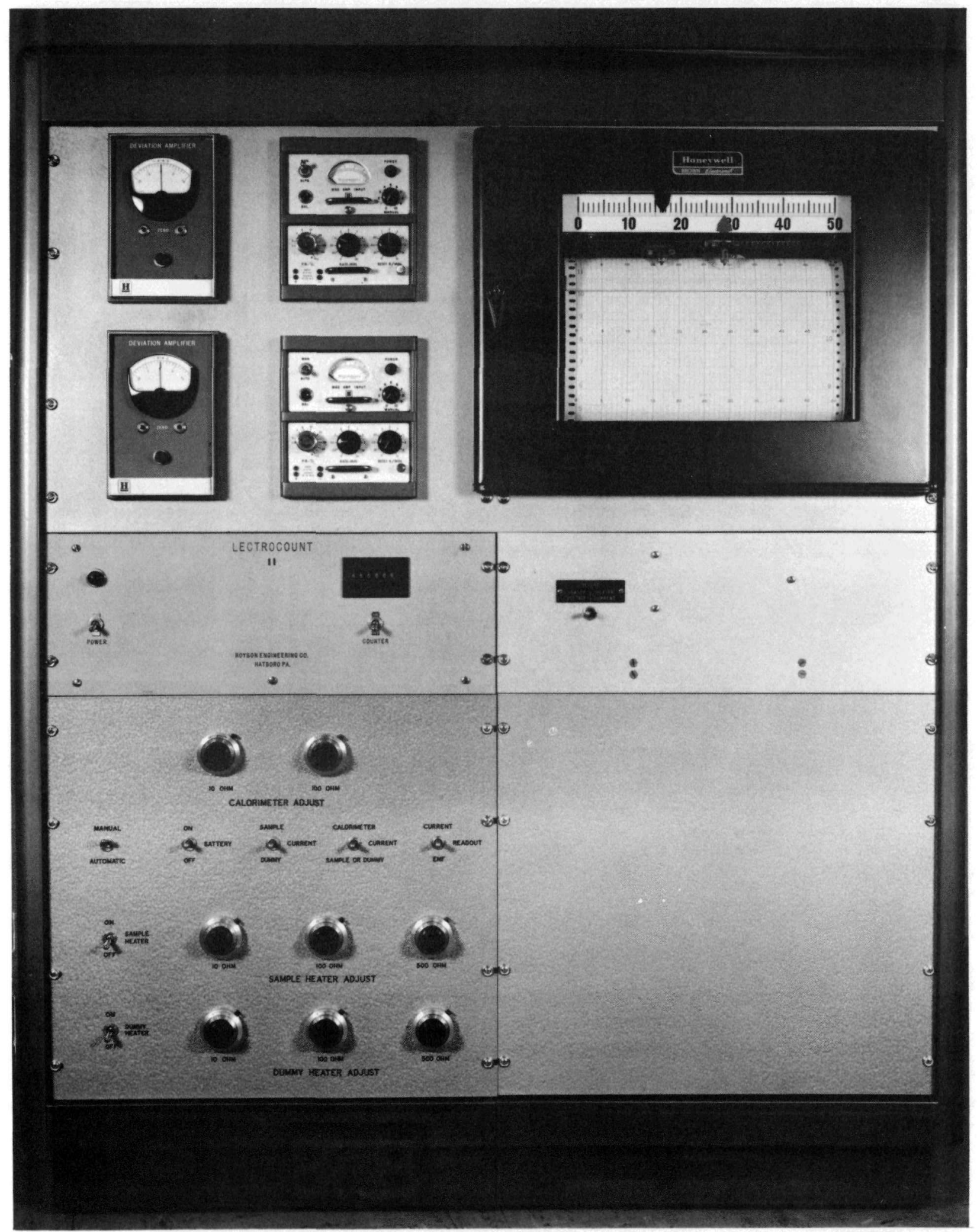

549

Fig. 8. Control Cabinet for Twin Calorimeter 


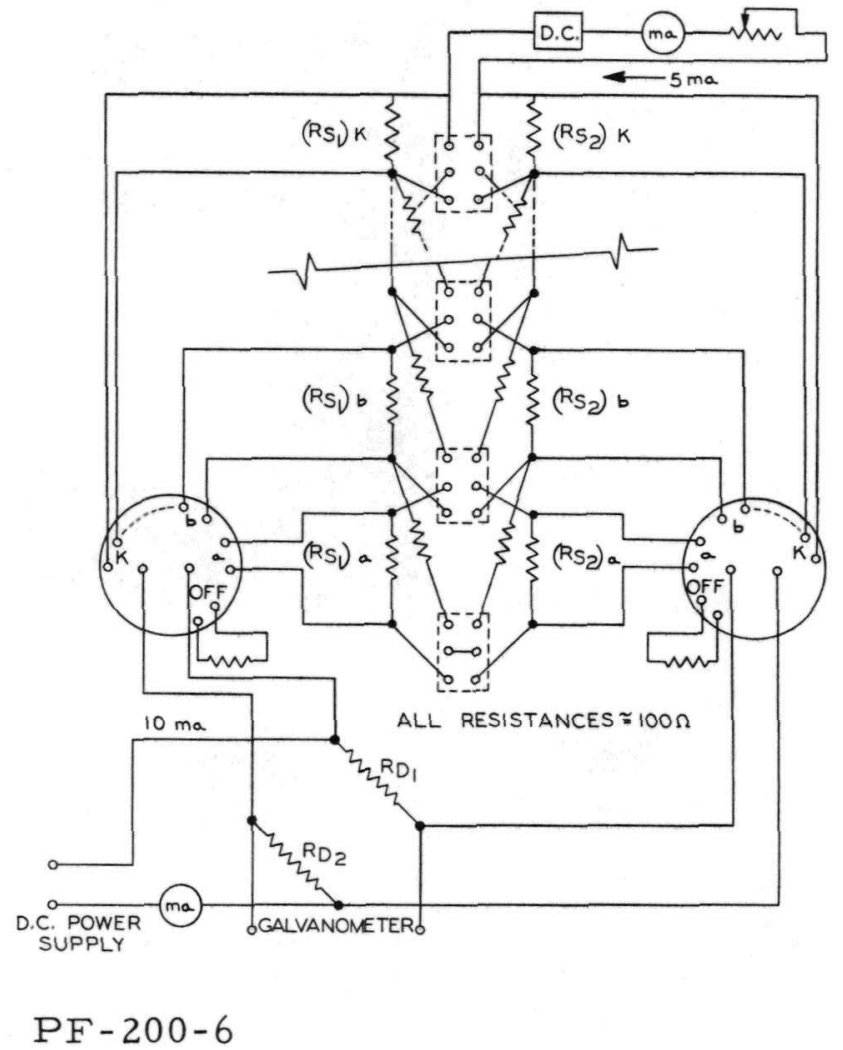

Fig. 9. Wiring Diagram for Multiple Arrangement of Twin Calorimeter 


\section{THE RATE CALORIMETER}

A rate calorimeter essentially as described by A. G. White(6) has been designed and constructed as shown in Figure 10. The calorimeter consists of a metal block enclosed in a constant-temperature environment. There are two thermistors embedded in the metal block. When a previously charged condenser is discharged through the thermistors, current will flow in the circuit only during heating, that is, while the resistance of the thermistor is changing. By measurement of the current prior to and after inserting the sample, the rate of energy release may be calculated, as indicated in Figure 11 .

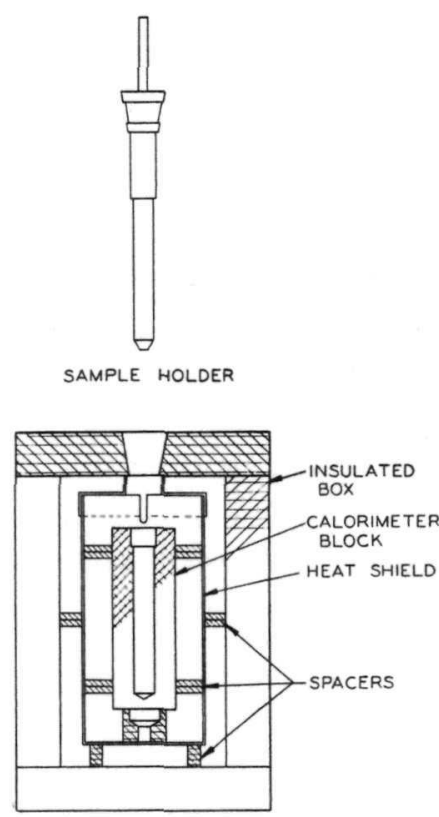

$P F-200-8$

Fig. 10

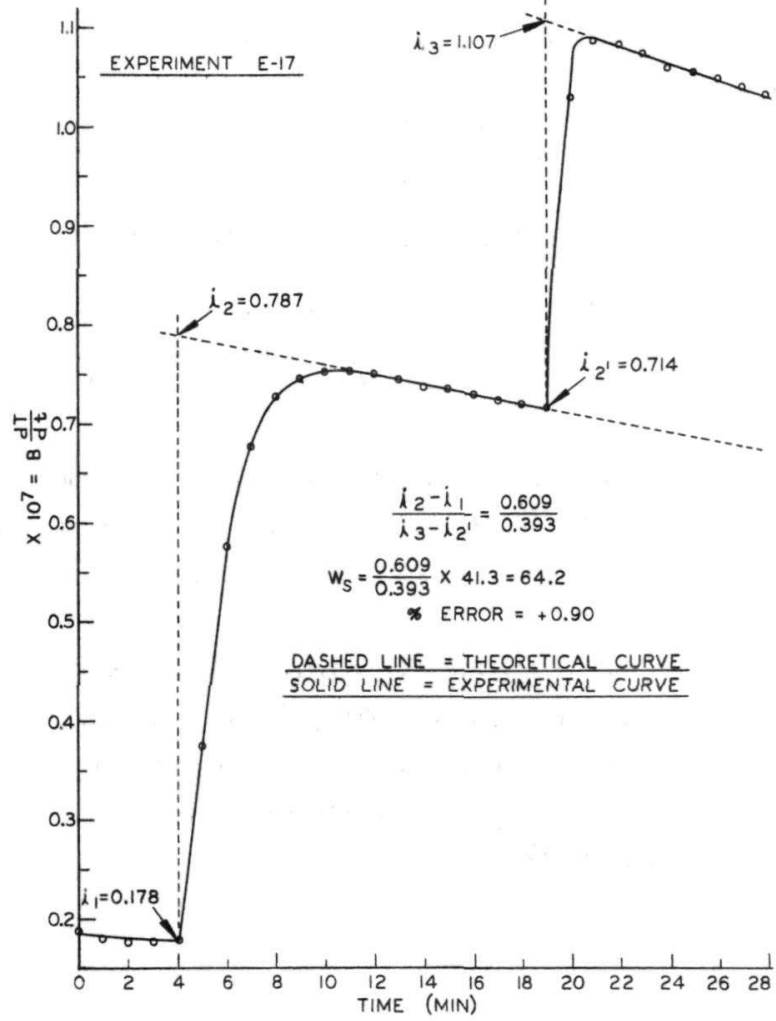

$P F-200-9$

\section{Fig. 11}

\section{Rate Calorimeter Rate Calorimeter, Current-Time Plot}

The calorimeter may be modified to accommodate samples of various geometry, rate of energy release, and sensitivity. It appears that the temperature of the surroundings is not critical as long as it remains relatively constant, since the calorimeter is calibrated at the end of each experiment.

The rate calorimeter is suitable for the determination of thermal effects, where there is a steady rate of heat emission. This method is not 
as accurate as the differential method. The accuracy expected is in the vicinity of $1-2$ percent.

The theory of the rate calorimeter is given by White. (6) He derived the following relationship between current readings and source strength:

$$
\frac{i_{2}-i_{1}}{B}=\frac{W}{C+\delta c},
$$

where

$$
\begin{aligned}
& W=\text { rate of heat input into the calorimeter } \\
& i_{1} \text { and } i_{2}=\begin{array}{l}
\text { galvanometer reading prior to and after insertion of } \\
\text { sample }
\end{array} \\
& C=\text { heat capacity of calorimeter } \\
& \delta c=\text { heat capacity of sample } \\
& B=\text { constant involving the capacitance of condensers. }
\end{aligned}
$$

The value of $i_{2}$ is established by observing the current reading for several minutes after insertion of the sample and then extrapolating back to the time when the last observation of $i_{1}$ was made.

The rate of heat input into the calorimeter can be obtained from Equation 2 if the values of $(C+\delta c)$ and $B$ are known. These quantities, however, can be eliminated by taking several additional current readings while electrically heating the calorimeter and obtaining a new current reading $i_{3}$. It can be shown that

$$
W=\left(\frac{i_{2}-i_{1}}{i_{3}-i_{2}}\right) W_{e},
$$

where

$\mathrm{W}_{\mathrm{e}}=$ power input during electric heating.

Equation 3 is the fundamental assay equation for this rate calorimeter.

$\underline{\text { Design Variables }}$

Further theoretical work has led to the definition of the constant B and gives a basis for changing design variables to improve accuracy of the instrument. 
White ${ }^{(6)}$ derived the following relationships for the rate of temperature change and for current as a function of this rate:

$$
\begin{aligned}
& \frac{d T}{d t}=\left[\frac{W}{C}-\frac{L}{C}\left(T_{0}-T_{s}\right)\right] e^{L_{t} / C} ; \\
& i=2 E F a\left[\frac{R_{r} R_{t}}{\left(R_{t}+R_{r}\right)^{2}}\right] \frac{d T}{d t},
\end{aligned}
$$

where

$$
\begin{aligned}
\mathrm{T}_{0} & =\text { initial temperature of calorimeter } \\
\mathrm{E} & =\text { voltage impressed on bridge } \\
\mathrm{a} & =\text { temperature coefficient of resistance of thermistor } \\
\mathrm{F} & =\text { capacitance of capacitor } \\
\mathrm{R}_{\mathrm{r}} & =\text { resistance of a bridge arm } \\
\mathrm{R}_{\mathrm{t}} & =\text { resistance of one thermistor } \\
\mathrm{L} & =\text { thermal leakage of calorimeter } \\
\mathrm{t} & =\text { time. }
\end{aligned}
$$

It is apparent from Figure 11 that in order to obtain precise results, i must be accurately determined and the slope must be correctly extrapolated.

Equation 5 shows that the capacitor current i can be used to give a correct value of $\mathrm{W}$ in Equation 3 if the capacitor leakage current is small and

$$
B=2 E F a \frac{R_{r} R_{t}}{\left(R_{t}+R_{r}\right)^{2}}=\text { constant }
$$

The above conditions were met by the use of low-leakage, tantalum electrolytic capacitors and by keeping the overall temperature increase small. It can also be shown that matched pairs of thermistors are not necessary, and that proper balancing of bridge resistance will decrease any excess capacitor leakage produced as a result of thermistor resistance difference. Correct extrapolation of the slope depends primarily upon:

1. calorimeter lag time;

2. ambient temperature change;

3. the slope of the curve $\left(\frac{d^{2} T}{d t^{2}}\right)$. 
Equations have been derived yielding curves that closely resemble the actual experimentally determined curve of $i$ vs $t$ (see Figure 11). These equations help explain the effect of lag time on the obtainable accuracy. It is evident from Figure 11 that a small lag time is desirable. Lag time depends primarily upon the thermal diffusivity of the calorimeter material, the characteristics of the temperature-sensing device, and the clearance between sample and the container.

When Equation 3 is used, ambient temperature changes are partially compensated for. It appears, therefore, that a constant-temperature environment is not imperative.

It should also be evident from Figure 11 that a nearly horizontal slope (i.e., $\mathrm{d}^{2} \mathrm{~T} / \mathrm{dt}^{2}$ approaching zero) is desirable, since this reduces extrapolation errors. It can be shown that this slope varies with calorimetric specific heat, $C$, and calorimeter thermal leakage, L. The following equations show this dependence:

$$
\begin{aligned}
& \frac{d(d T / d t)}{d T / d t}=\left(\frac{L T}{C}-1\right) \frac{d c}{C}(\text { Constant } L) ; \\
& \frac{d(d T / d t)}{d T / d t}=-\left(\frac{L T}{C}\right) \frac{d L}{L}(\text { Constant } C) .
\end{aligned}
$$

As experimental variables cannot always be altered to the experimenter's convenience, correction factors have also been derived and can be applied where necessary. Three such correction factors are:

1. To account for thermistor heating,

$$
W_{s}=\frac{i_{2}-i_{1}}{i_{3}-i_{2}} W_{e}+\frac{\delta c}{C} W_{t} \text {, }
$$

where

$$
\mathrm{W}_{\mathrm{t}}=\text { thermistor heating (due to bridge current) }
$$$$
\frac{\delta \mathrm{c}}{\mathrm{C}} \mathrm{W}_{\mathrm{t}}=\text { the correction factor. }
$$

2. To account for environmental temperature changes,

$$
\frac{\mathrm{dT}}{\mathrm{dt}}-\frac{\mathrm{L}}{\mathrm{C}}\left(\mathrm{T}_{\mathrm{s}}-\mathrm{T}_{\mathrm{s} 0}\right)=\frac{\mathrm{W}}{\mathrm{C}}-\frac{\mathrm{L}}{\mathrm{C}}\left(\mathrm{T}-\mathrm{T}_{\mathrm{s} 0}\right)
$$

where

$\mathrm{T}_{\mathrm{s} 0}=$ environmental temperature at time $\mathrm{t}=0$. 
3. To account for lag time,

$$
\frac{d T}{d t}=\left(\frac{d T}{d t}\right)_{o b s}\left(\ell-e^{-t / l}\right)
$$

where

$$
\ell=\text { lag time. }
$$

The two properties that are of importance in materials used for the calorimeter block are heat capacity and thermal diffusivity. Low heat capacity increases capacitor current with a given bridge arrangement, but the slope of $i$ vs $t$ increases with decreasing heat capacity. To reduce thermal lag, large thermal diffusivity is desirable. From the standpoint of these properties, copper and aluminum are the most suitable base metals. For a given volume, copper has twice the heat capacity of aluminum and has only slightly less thermal diffusivity. Copper should be useful for measuring large sources, whereas aluminum will be necessary when source strengths are small, say less than $200 \mathrm{~mW}$.

The use of high-resistance thermistors has a twofold advantage. Larger thermistor resistance will decrease battery drainage, thereby maintaining a more constant battery voltage. Since the thermistor heating error is related to $E^{2} / 4 R_{t}$ (where $E$ is the battery voltage and $R_{t}$ the thermistor resistance), a large value of $R_{t}$ will obviate the necessity of a correction factor.

$\underline{\text { Preliminary Experimental Work }}$

Initially, the experimental work was carried out with a Leeds and Northrup Type "K" potentiometer and an electronic galvanometer measuring the voltage drop across a standardized resistance, instead of the moving coil galvanometer used by White.(6) It can be shown that the error introduced by this method is damped out during the period when lag effects predominate and, consequently, it is not in itself a source of error. This can be shown as follows:

$$
\frac{i}{B}=\frac{d T}{d t}\left(l-e^{-t / F R}\right)
$$

where

$$
\begin{aligned}
& F=\text { condenser capacitance } \\
& R=\text { resistance in series with capacitor. }
\end{aligned}
$$

By proper choice of $R$ the exponential can be made to approach zero. 
The current input into the calorimeter heater was also determined by measuring the voltage drop across a standard resistance. The circuit diagram used is given in Figure 12. To be able to match the value of resistors to the resistance of the thermistors, 5000-Ohm thermistors were used in series with $5000-O h m$, variable precision resistances. A separate electrical heater, which could be inserted into the calorimeter sample can, was used as a power source for calibration. The method outlined by White ${ }^{(6)}$ was used for operating the calorimeter and interpreting the data obtained. Sample data and methods for extrapolation and for calculation are shown in Figure 11, which is a plot of the data obtained in one of the experiments. The curve is typical and similar to those obtained by White. (6) The accuracy of the various runs varied between 0.5 and two percent.
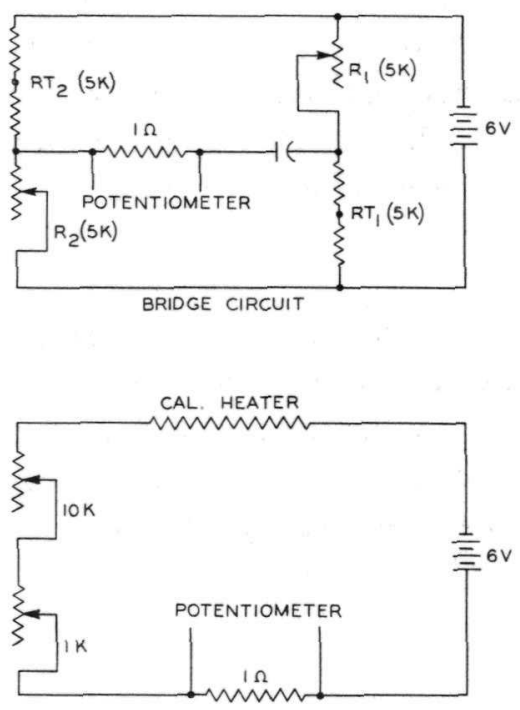

$P F-200-12$

Fig. 12

Experimental Circuit

Diagram for Rate

Calorimeter
The 5000-Ohm thermistors were subsequently replaced by 50,000-Ohm thermistors, which behaved as expected. Placing the calorimeter into a constant-temperature bath, although decreasing the scatter of data, did not produce improvement in the accuracy, which remained at one percent. Redesign of heat shields and introduction of insulating material around the block caused no observable change in the performance of the calorimeter. Replacement of the aluminum block with copper blocks of the same size and double the size produced the results predicted. Condensers of lower leakage value produced more consistent results and better accuracy.

The foregoing experiments indicated the feasibility of measuring radioactive source strength by the rate calorimeter. The accuracy of one to two percent claimed by White was achieved even with the relatively crude setup used. It was believed that by the use of auto-

matic instrumentation including high accuracy picoammeter, instead of the potentiometric measurement, greater accuracy and reliability can be obtained.

Leakage Value

Leakage values for the aluminum calorimeter were determined to aid in investigating sources of error. The values were obtained from a graph of current vs time by utilizing the following equation:

$$
L=\frac{C}{t_{2}-t_{1}} \ln \frac{i_{1}}{i_{2}} .
$$


The following values were averaged from several curves.

$\begin{array}{cr}\text { Source Strength }(\mathrm{mV}) \text { avg } & \frac{L\left(\mathrm{cal} / \mathrm{sec}-{ }^{\circ} \mathrm{C}\right)}{75} \\ 165 & 0.028 \pm 0.002 \\ & 0.058 \pm 0.002\end{array}$

The exact temperatures of the calorimeter were not obtained, as there were no provisions for temperature measurements. The temperature difference between the two cases was calculated to be less than $1 / 4^{\circ} \mathrm{C}$. For such a small temperature difference, it is surprising that different leakage values are obtained.

Modified Assay Procedure

A suggested modification in the procedure for assaying productionquantity fuel elements is described below. This procedure makes use of an instrument constant that can be determined during the initial calibration. The procedure should reduce the instrument time necessary per determination to between 15 and $20 \mathrm{~min}$. Longer times will still be required when material of different shapes and content are assayed.

The validity of the basic assumption that capacitor current is proportional to $\mathrm{W}$ was checked by plotting current changes (read as voltage changes on the potentiometer) against power input to the calorimeter. As expected, a linear relationship (see Figure 13) was obtained.

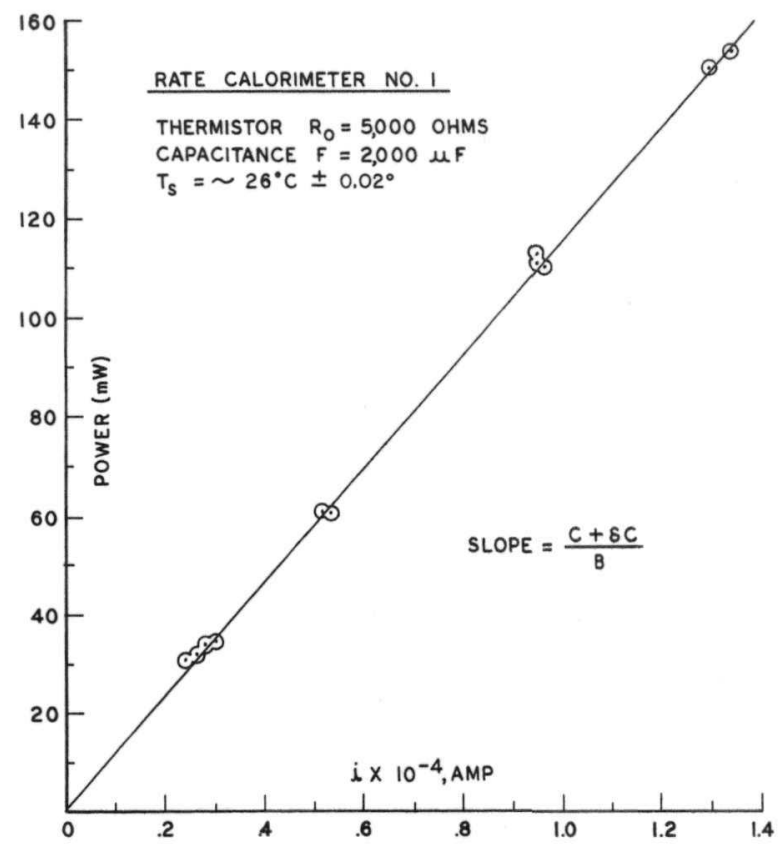

$\mathrm{PF}-200-7$

Fig. 13. Calibration Curve for Rate Calorimeter
The slope of the curve, $(C+\delta c) / B$, where $B$ and $C$ are instrument constants, depends upon the capacitance and the bridge characteristics. The heat capacity of the sample, $\delta c$, will be small in comparison with $C$, and any changes in the value of $(C+\delta c) / B$ due to small variations in the value of $\delta \mathrm{c}$ will be greatly reduced. Consequently, production-type fuel elements, i.e., size and shape remaining constant, should yield the same value for the slope.

In making a determination, the value obtained from the first portion of the curve is

$$
e_{2}-e_{1}=\left(\frac{B}{C+\delta c}\right) W
$$


Now, if $\mathrm{W}$ for a fuel element is first obtained by the usual procedure (using the entire curve), the value of the slope can be calculated from the above equation and then used repeatedly in subsequent determinations. The constant can also be determined by calibrating against a standard, which will commonly be the case.

Further Work on the Rate Calorimeter

In view of results of the preliminary work on the rate calorimeter, a multirange picoammeter and a Speedomax recorder were obtained to perform additional experiments to evaluate further the usefulness of the rate calorimeter.

After use of the new instrumentation with a temporary control panel, the electrical circuitry for the control panel was decided upon, and the instruments and control panel were installed into a cabinet. The control circuit is shown in Figure 14, the assembled instrument cabinet in Figure 15.

The control circuit (see Figure 14) contains two 50,000-Ohm thermistors arranged in a bridge with two 55,000-Ohm variable resistances. Each of the latter consists of one 50,000-Ohm and one 5,000-Ohm highresolution potentiometer connected in series, which makes it possible to vary the resistance from 0 to 55,000 Ohms to allow the use of thermistors

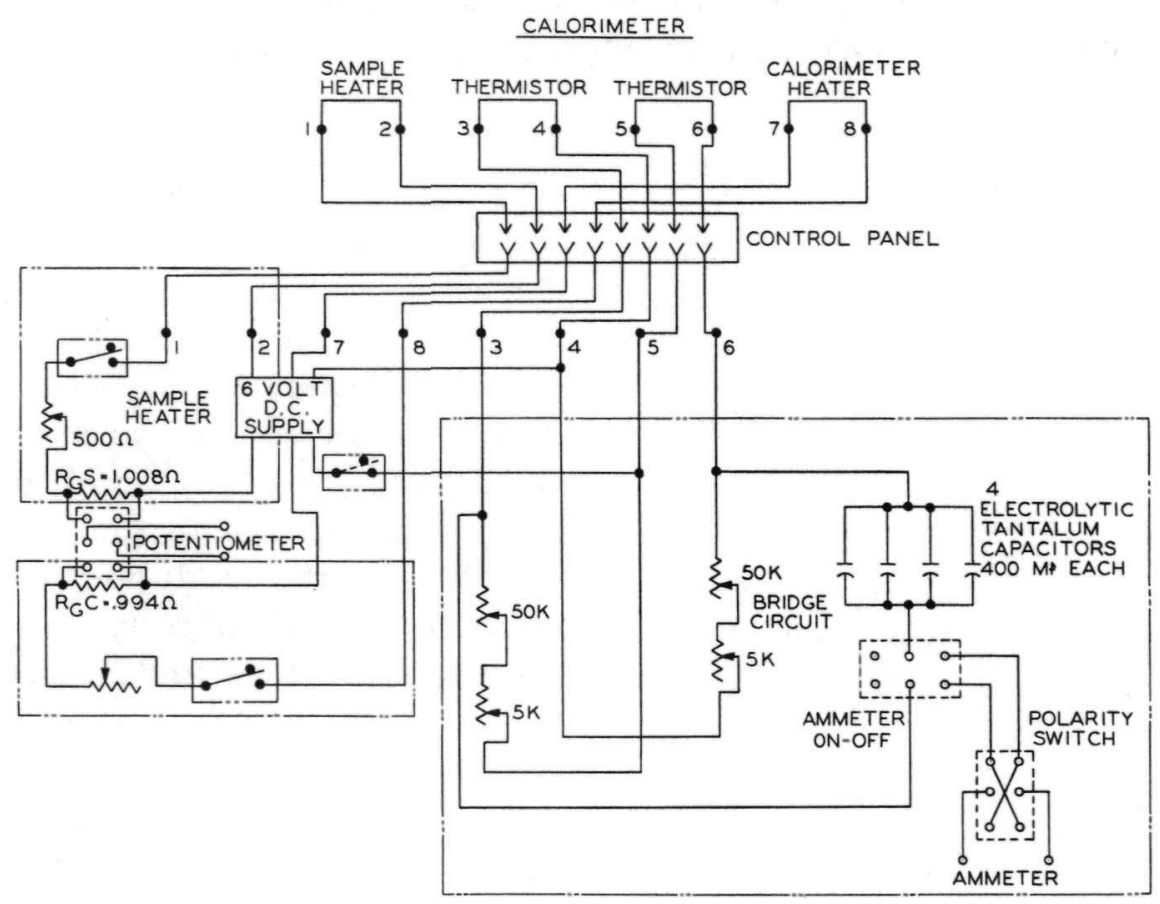

PF $-200-13$

Fig. 14. Circuit Diagram for Rate Calorimeter 


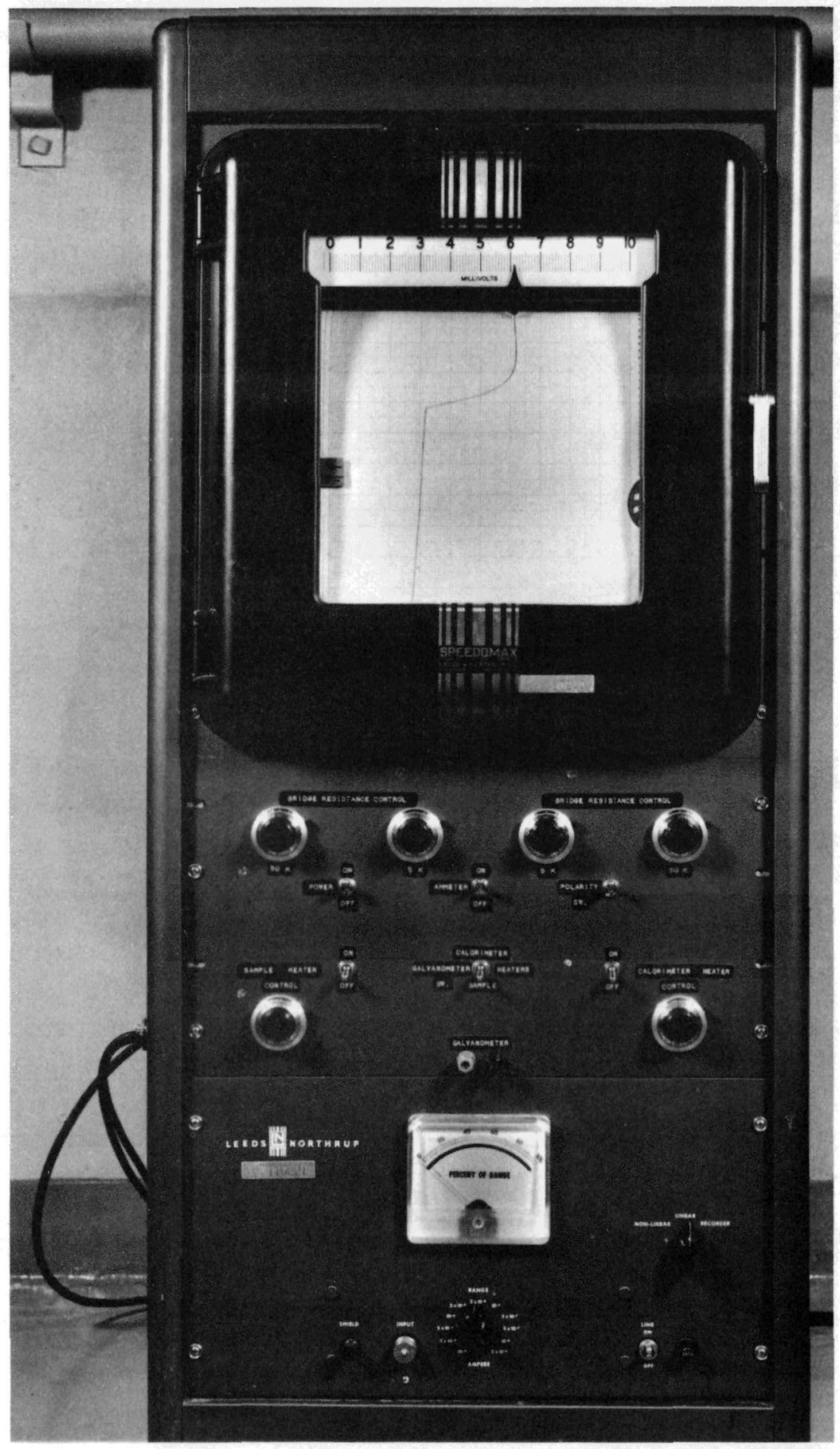

\section{3}

Fig. 15. Control Cabinet for Rate Calorimeter 
with different resistances. The capacitor consists of four 400- $\mu \mathrm{F}$, nonpolarized tantalum electrolytic condensers in parallel, giving a total capacitance of $1600 \mu \mathrm{F}$. The sample-heater current and the calibrating-heater current are adjusted with $500-\mathrm{Ohm}$ high-resolution variable resistance and are measured with a Leeds and Northrup Type-K potentiometer, as potential drops across one-Ohm resistors. The exact values of the one$\mathrm{Ohm}$ resistors were determined with a Wheatstone bridge and are given in Figure 14.

Originally, the calorimeter heater coil was wound with a single winding. To reduce spurious electrical effects, the coil later was rewound bifilarly, with some resulting benefit.

A number of different types of capacitors were tested in the circuit. The nonpolarized tantalum electrolytic capacitors were found to work most satisfactorily.

$\underline{\text { Results }}$

A number of tests were carried out with the calorimeter using both an electrical heater and aluminum-jacketed plutonium slugs as the heat source. The results were comparable and similar, and the current-vstime graphs obtained on the recorder were of the same type. A characteristic curve is shown in Figure 16, which also illustrates the ideal and the

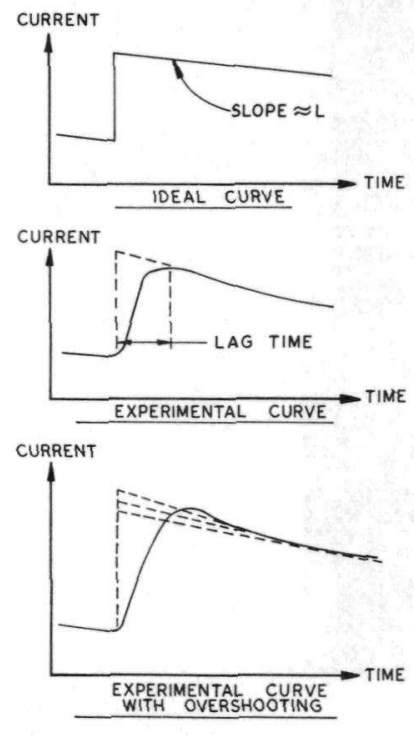

$\mathrm{PF}-200-14$

Fig. 16. Current-Time Curves from Rate Colorimeter desired shape of the curves. The graphs obtained on the recorder at the beginning of the test cycle were generally characterized by a slight "overshoot," followed by a gradual decrease of current with time, but the decrease in current was not always linear with time. When the curve deviated from linearity it was very difficult and at times impossible to extrapolate to zero time reliably; as a consequence, the accuracy and the reliability of the measurements were not within the desired limits. When the currentvs-time curve had a linear portion, the extrapolation to zero time yielded results of better than the two-percent accuracy anticipated from this method. Figures 17 and 18 are recorder charts showing the "overshoot" and the desirable conditions, respectively.

Replacement of the aluminum heat sink by one made of copper caused no significant change in the performance of the calorimeter.

The time needed for one determination was about $90 \mathrm{~min}$. The reason for this longer-than-anticipated time of operation was that a period of about 30 min was needed to permit the reestablishment of thermal equilibrium within the calorimeter. This allowed the reading on the ammeter to drop to a level where a new test could be carried out. 


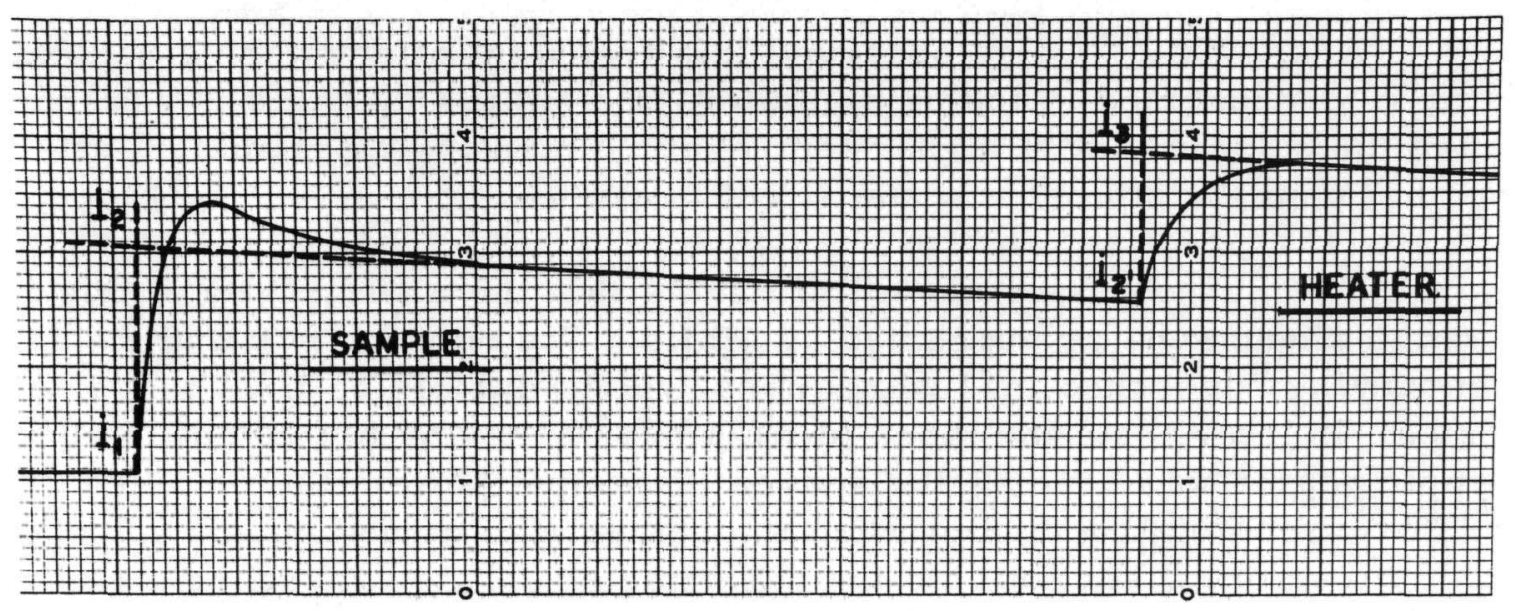

673

Fig. 17. Recorder Chart Showing Overshoot When Sample Inserted in Rate Colorimeter

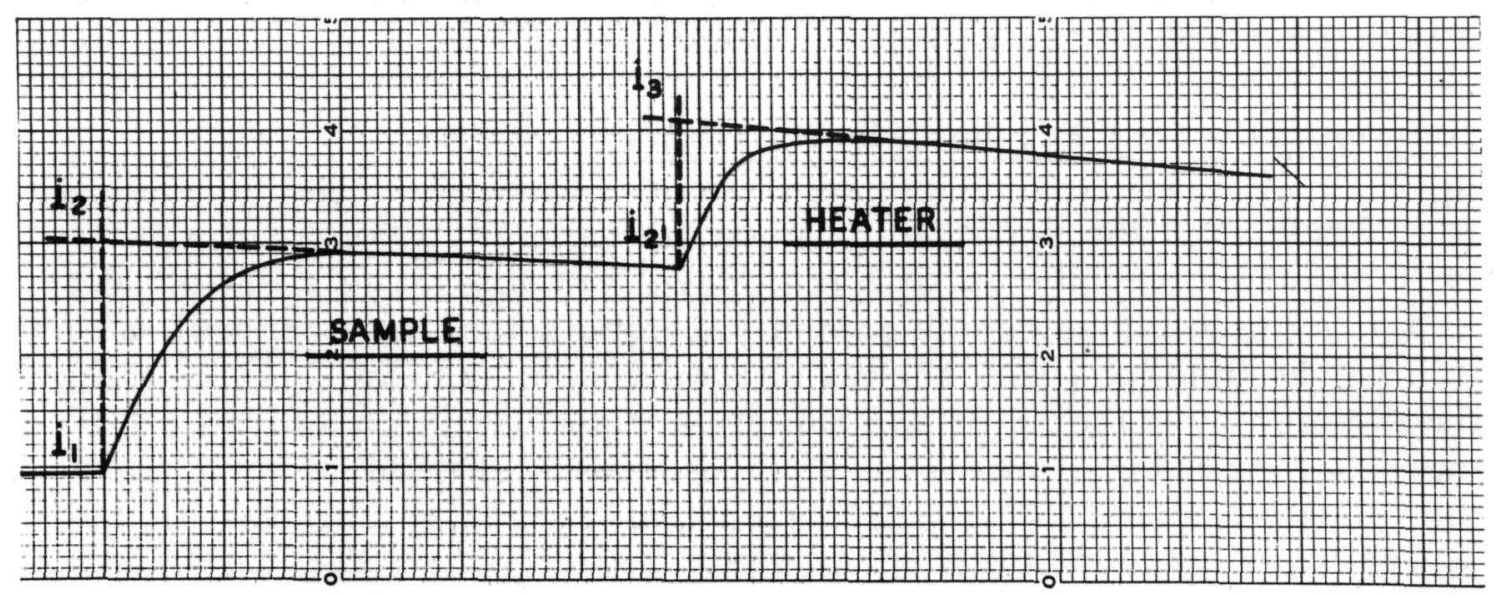

673

Fig. 18. Recorder Chart Showing Desired Curve for Rate Colorimeter

Sample calculations for the rate colorimeter are given in Appendix B.

Discussion of Results

The departure from linearity of the current-vs-time graph made it very difficult, and at times impossible, to extrapolate the current reading back to zero time with any degree of reliability. This affected the accuracy of the determination in three cases. When the plots were linear, however, the measurements obtained were better than two percent accurate. 
A. G. White ${ }^{(6)}$ also observed this transient effect when a radioactive sample was inserted in the calorimeter. He claims that this is caused because the sample is at a higher temperature than the calorimeter; after thermal equilibrium occurs, the effect vanishes.

Two observations seem to indicate that the nonlinearity is due to thermal phenomena as suggested by White. The nonlinearity and its accompanying "overshooting" were most evident during the first test in a series. In later tests the more ideal, linear behavior occurred. When the sample heater was used as the source of sample power, the nonlinearity and "overshooting" occurred when the heater was turned on and allowed to warm up before insertion into the calorimeter. This procedure more closely duplicates the test with radioactive materials. If, however, the heater was turned on while in the calorimeter, causing a more gradual heat influx, no "overshooting" or nonlinearity occurred.

The time needed for one determination was longer than anticipated. It is possible that the speculated advantage over other calorimetric methods will not be realized. It is conceivable that the twin calorimeter may be operated as a multiple calorimeter, bringing the time needed for a determination into the range of the rate calorimeter.

$\underline{\text { Recommendation for Further Modifications }}$

Presently, the recorder is used with the zero point set at midscale. This is done because the capacitor current usually travels in both directions during a test and changing the polarity during a test by means of the polarity switch on the control panel seems to induce some error. Use of the midscale reduces by a factor of two the magnitude of the measurable current change and, therefore, increases the experimental error. A larger portion of the full scale could be used if the recorder were adjusted so that the zero were, let us say, at 0.2 of full scale from the left side. Precautions must also be taken to minimize external electrostatic effects.

Six-Volt storage batteries were used as DC power supplies. These batteries exhibited slight variations in emf that make it necessary to use mean values of heater power and possibly having a significant effect on the capacitor current. In the equation for capacitor current,

$$
i=B \frac{d T}{d t}
$$

$B$ is assumed to be a constant. In the terms of directly measurable quantities $B$ is given by Equation 6. It can be shown that the change in the term $R_{r} R_{t} /\left(R_{t}+R_{r}\right)^{2}$ is negligible during a normal test. It is seen, however, that a significant variation in $E$ would have a significant effect on the value of $B$. Therefore, the variation in battery emf may be a cause of the nonlinear 
dependence of current vs time during the rating period. Ideally then, a constant source of electric current is desired.

Some improvement in accuracy may be obtained by adjustment of the volume of the calorimeter block, i.e., its heat capacity, to the size of the sample heat source. This problem has been discussed earlier.

Recommendation for Use

The rate calorimeter has several advantages over the twin calorimeter. It is simpler and less costly to build. Being insensitive to slight changes in room temperature, it does not need a constant temperature environment.

There are disadvantages as well. Operation is not as straightforward as was expected. Operation time was longer than had been expected. A single test with the rate calorimeter took approximately an hour to perform, whereas approximately one to two hours were required with the twin calorimeter. Using the rate calorimeter, however, there is a period of about half an hour between consecutive runs which has to be allowed for the reestablishment of thermal equilibrium within the calorimeter. No such period is required with the operation of the twin calorimeter. Readings and adjustments must be made with the rate calorimeter during the test, whereas the twin calorimeter requires attention only at the beginning and at the end of a test. More time is required in the interpretation of the results and for the necessary calculations with the rate calorimeter.

The results with the rate calorimeter are less accurate and reliable than those obtained with the twin calorimeter. Even if exactness is introduced into the process of extrapolation, it is still physically limited to one to two percent accuracy. It seems that except where cost or the need of a constant temperature environment are factors of importance, the twin calorimeter could be used to better advantage. 
The following is a comparison of the rate and twin calorimeters:

1. Cost: The construction of the twin calorimeter is more expensive than that of a rate calorimeter; however, without elaborate instrumentation, the difference in cost should not be enough to rule out the use of the twin calorimeter.

2. Size: If space requirements are important, the twin calorimeter has the disadvantage of needing a more closely controllable constanttemperature environment, which requires more space.

3. Accuracy: The twin calorimeter surpasses the rate calorimeter in both accuracy and reliability of results:

Rate calorimeter: $\pm 2.0 \%$;

Twin calorimeter: $\pm 0.25 \%$ or better.

4. Time Involved: The difference in the operating time is small, and it seems possible that redesign of the twin calorimeter as a multiple calorimeter can make its operating time significantly shorter than that of the rate calorimeter. The advantage that the twin calorimeter has in this respect is that the calorimeter constants have to be determined only once, whereas the rate calorimeter demands such an evaluation with each test.

5. Adaptability to Production: The rate calorimeter is limited to three or four tests per 8-hr day, whereas a multiple twin calorimeter could be adapted to measure a larger number of samples. 


\section{ACKNOW LEDGMENTS}

William K. Miller Jr. has conducted the experiments on the twin calorimeter and part of the experimental work on the rate calorimeter. His contribution to the program is gratefully acknowledged. The helpful suggestions concerning twin calorimetry by Dr. Leroy V. Jones and Mr. Kenneth Jordan of Mound Laboratory are greatly appreciated. 


\section{BIBLIOGRAPHY}

1. Swietoslawski, W., Microcalorimetry, Rheinhold Publ. Corp., New York (1946) p. 42.

2. Ibid., p. 44.

3. Hood, W. L., and Rogers, A. J., Polonium, Ed. by Moyer, H. V., TID-5221 (1956) p. 262.

4. Jones, L. V., and Jordan, K., Mound Laboratory, personal communication.

5. Ref. 1., p. 49 .

6. White, A. G., A Calorimetric Method of Determining the Energy Output of Radioactive Materials, J.Sci. Instr. 33, 230 (1956).

7. Beamer, W. H., and Easton, W. E., Physical Properties of Polonium III; Half-life of Polonium, J. Chem. Phys. 17, 1298 (1949).

8. White, W. P., The Modern Calorimeter, The Chemical Catalog Co., New York (1928).

9. Rogers, A. J., Polonium (see Ref. 3), Ch. 10, "Calorimetry," p. 272.

10. Gunn, S. R., Radiometric Calorimetry at the Livermore Site of the University of California Radiation Laboratory, UCRL-4547 (July 1, 1955).

11. Stull, D. R., et al., A Constant Power Source for Calorimetry, Rev.Sci. Instr. 24, 1003 (1953).

12. Buzze11, A., and Sturtevant, J。M., A Voltage Integrator, Ibid., 19,688 (1943).

13. Perkins, J. F., and King, R. W., Energy Release from the Decay of Fission Products, Nucl. Sci. Eng. 3 , 726 (1958) Vol. 3. 


\section{APPENDIX A}

Here is given an example of data and calculations in establishing source strength with the twin calorimeter. (3) The source strength is calculated in Watts.

(a) Initial bridge voltage: $\mathrm{E}_{\mathrm{B} 0}=0.003671 \mathrm{~V}$.

(b)* Sample heater is turned on and after thermal equilibrium has been established:

$$
\begin{aligned}
\mathrm{E}_{\mathrm{B} 1} & =0.002129 \mathrm{~V} ; \\
\mathrm{E}_{\mathrm{B} 1} & =\mathrm{E}_{\mathrm{B} 1}-\mathrm{E}_{\mathrm{B} 0}=-0.001542 \mathrm{~V} .
\end{aligned}
$$

Resistance of standard resistors:

$$
\begin{aligned}
\mathrm{R}_{\mathrm{GS}} & =1.002 \mathrm{Ohms} ; \quad \mathrm{R}_{\mathrm{GD}}=1.004 \mathrm{Ohms} . \\
\mathrm{E}_{\mathrm{GS}} & =0.079978 \mathrm{~V}, \quad \mathrm{I}_{\mathrm{GS}}=\mathrm{E}_{\mathrm{GS}} / \mathrm{R}_{\mathrm{GS}}=0.07981836 \mathrm{Amp} . \\
\mathrm{F}_{\mathrm{S}} & =\mathrm{R}_{\mathrm{HS}}=31.18 \mathrm{Ohms}(\text { sample side heater }) \\
\mathrm{W} & =\mathrm{R}_{\mathrm{HS}} \mathrm{I}^{2}=(31.18)(0.07981836)^{2}=0.1986468 \mathrm{~W} .
\end{aligned}
$$

Thus the sensitivity in the sample side is

$$
\mathrm{S}_{\mathrm{S}}=\Delta \mathrm{E}_{\mathrm{B} 1} / \mathrm{W}=-0.001542 / 0.1986468=-7.76252 \times 10^{-3} \mathrm{~V} / \mathrm{W} \text {. }
$$

(c)* Dummy and sample heaters in series are turned on and after thermal equilibrium has been established:

$$
\begin{aligned}
& \mathrm{E}_{\mathrm{B} 2}= 0.003665 \mathrm{~V} ; \\
& \Delta_{\mathrm{B} 2}= \mathrm{E}_{\mathrm{B} 2}-\mathrm{E}_{\mathrm{B} 0}=-0.000006 \mathrm{~V} . \\
& \mathrm{E}_{\mathrm{GS}}= 0.08086 \mathrm{~V}, \quad \mathrm{I}_{\mathrm{GS}}=\mathrm{E}_{\mathrm{GS}} / \mathrm{R}_{\mathrm{GS}}=\begin{array}{l}
0.08086 / 1.022= \\
0.08064471 \mathrm{Amp} .
\end{array} \\
& \mathrm{E}_{\mathrm{GD}}= 0.080975 \mathrm{~V} ; \quad \mathrm{I}_{\mathrm{GD}}=\mathrm{E}_{\mathrm{GD}} / \mathrm{R}_{\mathrm{GD}}=0.080975 / 1.004= \\
& 0.08065239 \mathrm{Amp} . \\
& \mathrm{I}_{\mathrm{av}}= 1 / 2\left(\mathrm{I}_{\mathrm{GS}}+\mathrm{I}_{\mathrm{GD}}\right) 0.08064855 \mathrm{Amp} . \\
& \mathrm{m}= \Delta \mathrm{E}_{\mathrm{B} 2} / \mathrm{I}_{\mathrm{av}}^{2}=-0.000006 /(0.08064855)^{2}= \\
&-0.92248 \times 10^{-3} \mathrm{~V} / \mathrm{Amp}^{2} \\
& \mathrm{~A}= \mathrm{F}_{\mathrm{S}} \mathrm{S}_{\mathrm{s}}-\mathrm{m} \\
&=(31.18)\left(-7.76252 \times 10^{-3}\right)-\left(-0.92248 \times 10^{-3}\right) \\
&=-0.2411289 \mathrm{~V} / \mathrm{Amp}^{2} .
\end{aligned}
$$

* Once $\mathrm{S}_{\mathrm{S}}$ and $\mathrm{A}$ are determined, they are used in subsequent calculations and need not be calculated again. 
(d) Sample is placed in calorimeter, dummy heater is turned on and after thermal equilibrium has been established:

$$
\begin{aligned}
E_{B_{3}} & =0.003662 \mathrm{~V} . \\
\Delta E_{B_{3}} & =E_{B_{2}}-E_{B_{0}}=-0.000009 \mathrm{~V} . \\
E_{G D} & =0.055990 \mathrm{~V} . \\
I_{G D} & =0.05590 / 1.004=0.05576693 \mathrm{Amp} . \\
C_{S} & =\frac{\Delta E_{B_{3}}+A_{G D}^{2}}{S_{S}}=\frac{-(0.000009)-(0.2411289) \times(0.05576693)^{2}}{-7.76252 \times 10^{-3}} \\
& =0.09776 \mathrm{~W} .
\end{aligned}
$$




\section{APPENDIX B}

Here is given an example of data and calculations for establishing source strength with the rate calorimeter:

Standard resistance, sample heater circuit: $1.008 \mathrm{Ohms}$.

Standard resistance, calorimeter heater circuit: $0.994 \mathrm{Ohm}$.

Sample heater, potentiometer reading: $E_{S}=0.044944 \mathrm{~V}$.

Calorimeter heater, potentiometer reading: $\mathrm{E}_{\mathrm{C}}=0.032972 \mathrm{~V}$.

Sample heater resistance, $R_{S}=25.26 \mathrm{Ohms}$.

Calorimeter heater resistance, $R_{C}=47.48$ Ohms.

Sample heater input, $\mathrm{I}^{2} \mathrm{R}_{\mathrm{S}}=\left(\frac{0.044944}{1.008}\right)^{2}(25.26)=\underline{0.0502 \mathrm{~W}}$.

Calorimeter heater input, $I^{2} R_{C}=\left(\frac{0.032972}{0.994}\right)^{2}(47.48)=0.05224305 \mathrm{~W}$

$$
\begin{aligned}
& i_{1}=39.9\left(2 \times 10^{-7}\right) ; \quad i_{2}{ }^{\prime}=56.7\left(2 \times 10^{-7}\right) ; \\
& i_{2}=58.7\left(2 \times 10^{-7}\right) ; \quad i_{3}=76.0\left(2 \times 10^{-7}\right) ; \\
& \frac{i_{2}-i_{1}}{i_{3}-i_{2}}=\frac{58.7-39.9}{76.0}=\frac{18.8}{19.3} . \\
& W=\frac{i_{2}-i_{1}}{i_{3}-i_{2}} W_{C}=\frac{18.8}{19.3}(0.05224305)=0.0509 \mathrm{~W} . \\
& \% \text { error }=\frac{0.0509-0.0502}{0.0502}=+1.39 \% .
\end{aligned}
$$

